\title{
The First Advisory Group Meeting (AGM) in Open and Distance Education
}

\author{
Georgios Giannoukos*, Ioannis Stergiou, Vasilios Hioctour, Sotiria Kallianta \\ Second Chance School, Greece \\ *g.giannoukos@gmail.com
}

\begin{abstract}
The main reason for someone to participate in an Open and Distance Education program is either the acquisition of professional skills on a given object, or the development of his existing skills and consequently their improvement. By carrying out Advisory Group Meetings (AGM) on specific issues related to the trainees, a deepening of their theoretical background and the practical aspects of their training takes place, which they all seek. In this paper we present in a concise way the course of such a meeting according to the extent that it may have, in which the theory is being associated with practice.
\end{abstract}

Keywords: Adult education, distance education, advisory group meetings

\section{Introduction}

Adult Education is defined as the systematic participation of adults in properly structured theoretical and practical processes on a given subject. Of course, to achieve this goal, various training models are used (Rogers, 1998, p. 77). Open and Distance Education is defined as "a series of teaching and learning strategies used by schools, colleges, open universities, departments of remote conventional college or university education and from distance learning private entities» (Keegan, 2001, p. 58). AGM is a Consultative Group Meeting between an instructor and a student, which is part of a distance education program. This meeting takes place at regular intervals and usually lasts 3-4 hours (Kokkos, 1998, p. 126).

a) Determining the educational goal of the first AGM: As is known, the first AGM has a "special significance" (Kokkos, 1998, p. 127), since the foundations are set for the course that is to be followed. This is when "the foundations of the learning process" will be set and the "processing of the key methodological issues" will take place (Kokkos, 1998, p. 127). The goal of the first AGM is to clarify the possibilities offered to the students by the studying program of Open and Distance Education, to provide explanations for any possible obscure points and the processing of the material given by dialogue (Kokkos, 1998, p. 126).

b) Determination of the first AGM's objectives: The objectives of the first AGM may be both of objective and subjective nature. (a) to familiarize the students with each other, as with the teacher and to build a team spirit (Kokkos, 2005, p. 132), (b) the creation of an appropriate contract (Polemis-Todoulou, 2005, p. 263. Kokkos, 2005, p. 129), (c) the development of trust between teacher and students, (d) discussion on the AGM program in order to adapt it to the needs of the learner, (e) clarification of both the purpose and the objectives of the theme in relation to the particular needs of each learner with the help of discussion, (f) details concerning the structure and the way of writing the work, the manner of indicating references and literature, (g) formulating the basic philosophy of Open and Distance Education.

- Having preceded an electronic request for the deployment of each of the trainees $\mathrm{CV}$, as well as their study, to ascertain the particular inclinations, needs and interests, the most effective way to structure the presentation for the benefit of all can be found.

- We select the method of setting up groups among students to meet each other and then everyone can present to his "neighbour".

- We select the method of presentation to introduce the program and its basic philosophy to the learners in the most complete way possible. 
Table 1: Stages of the first AGM

\begin{tabular}{|c|c|c|c|}
\hline & Stage A & Stage B & Stage C \\
\hline Leaning objectives & Acquaintance - Contract & $\begin{array}{l}\text { Discussion about the } \\
\text { program and } \\
\text { presentation of the } \\
\text { basic philosophy }\end{array}$ & $\begin{array}{l}\text { Customizing } \begin{array}{l}\text { the Details on the structure } \\
\text { program to specificand writing of the work } \\
\text { needs (1) }\end{array}\end{array}$ \\
\hline Skill objectives & & & $\begin{array}{l}\text { Presentation of the Award of exemplary } \\
\text { theoretical background work }\end{array}$ \\
\hline Stance objectives & & $\begin{array}{l}\text { Viewing of the positiv } \\
\text { aspects of the program }\end{array}$ & $\begin{array}{l}\text { e Development of a Examples of positive } \\
\text { creative predispositionutilization of the } \\
\text { regarding the program program }\end{array}$ \\
\hline Time duration & 30 minutes & 70 minutes & 40 minutes \\
\hline Training techniques & Team formulating (2) & Presentation (3) & $\begin{array}{l}\text { Practical exercise inPresentation } \\
\text { groups }\end{array}$ \\
\hline Teaching aids & & Slideshow projector & $\begin{array}{l}\begin{array}{l}\text { Potential use of a Distribution of flyers } \\
\text { blackboard }\end{array} \\
\text { with the key points of } \\
\text { the presentation }\end{array}$ \\
\hline
\end{tabular}

Linking educational techniques with adult learning principles: The educational technique of the first stage is connected to the fifth principle of adult learning, ie the development of interactive teacher- student relationships (Kokkos, 1998, p. 43). The educational technique of the second stage is connected to the third principle, ie the heuristic path to knowledge (Kokkos, 1998, p. 38). The education technique of the third first stage is connected to the second principle that is the placement of the student at the centre of the educational process (Kokkos, 1998, p. 36). Also it is connected to the first principle, where the preamble is associated with action, since the students discover the practical values and advantages of this method (Kokkos, 1998, p. 27). The educational technique of the fourth stage is connected to the fourth principle, which is to develop critical thinking, since the students now have the opportunity to compare their personal experience developed in the third stage, while the basic principles and conclusions are summarized at the end of the whole process by the teacher (Kokkos, 1998, p. 41).

\section{Conclusion}

The purpose of the first AGM is the clarification and development of the benefits arising from the topic of Open and Distance Education. Presentation and working groups were used as training techniques. To achieve the objectives set, the appropriate supervisory means were used along with discussion between the learners themselves and the teacher. The conclusions can be very useful to all trainees. They applied this method in their working groups and saw the possibilities it can offer. Finally, they gained experience on which they can develop their personal experiences from the application of this method in future.

\section{References}

Keegan, D. (2001). Basic principles of Open and Distance Education. Athens: Metaichmio.

Kokkos, A. (1998). The preparation of the Advisory Group Meetings. in: A. Kokkos, \& A. Lionarakis. Open and distance learning: Relationship between teachers and students. Volume II. (pp. 125-154). Patra: Hellenic Open University.

Kokkos, A. (1998). The opening of the first Advisory Group Meeting. in: A. Kokkos, \& A. Lionarakis. Open and distance learning: Relationship between teachers and students. Volume II. (pp. 155-186). Patra: Hellenic Open University.

Kokkos, A. (1998). Principles of Adult Learning. in: A. Kokkos, \& A. Lionarakis. Open and distance learning: Relationship between teachers and students. Volume II. (pp. 19-51). Patra: Hellenic Open University.

Kokkos, A. (2005). Adult Education Methodology: Theoretical Framework and Learning Conditions. Volume A. Patra: Hellenic Open University.

Polemi-Todoulou, M. (2005). Adult Education Methodology: The Development of the Group in Adult Education. Volume III. Patra: Hellenic Open University.

Rogers, A. (1998). Adult Education. Athens: Metaichmio. 